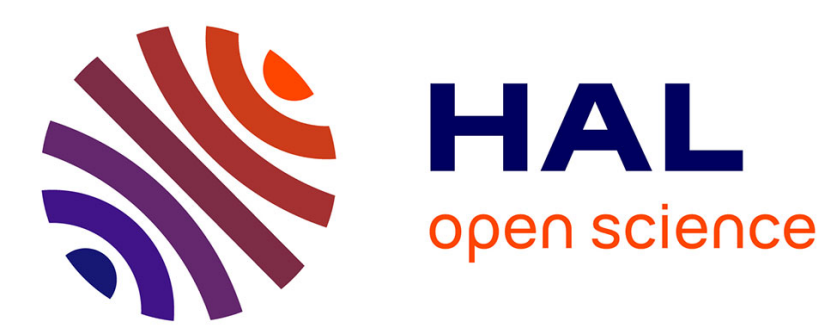

\title{
Evaluation model framework based on simulation for enterprise network negotiation mechanisms
}

\author{
Thibaud Monteiro, Marie-Claude Portmann, Smaïl Khouider
}

\section{To cite this version:}

Thibaud Monteiro, Marie-Claude Portmann, Smaïl Khouider. Evaluation model framework based on simulation for enterprise network negotiation mechanisms. Production Planning and Control, 2010, 21 (6), pp. 581-594. 10.1080/09537287.2010.489252 . hal-00584914

\section{HAL Id: hal-00584914 https://hal.science/hal-00584914}

Submitted on 11 Apr 2011

HAL is a multi-disciplinary open access archive for the deposit and dissemination of scientific research documents, whether they are published or not. The documents may come from teaching and research institutions in France or abroad, or from public or private research centers.
L'archive ouverte pluridisciplinaire HAL, est destinée au dépôt et à la diffusion de documents scientifiques de niveau recherche, publiés ou non, émanant des établissements d'enseignement et de recherche français ou étrangers, des laboratoires publics ou privés. 


\title{
Evaluation model framework based on simulation for enterprise network negotiation mechanisms
}

\author{
Thibaud Monteiro ${ }^{1,3}$ and Marie-Claude Portmann ${ }^{2}$ and Smaïl Khouider ${ }^{2,3}$ \\ ${ }^{1}$ PRES Université de Lyon, Université de Saint-Étienne, LASPI, 12 avenue de Paris, \\ 42300 Roanne, France \\ ${ }^{2}$ LORIA-INPL, École des Mines de Nancy, \\ Parc de Saurupt, CS 14 234, 54042 Nancy cedex, France
}

${ }^{3}$ LGIPM, École Nationale d'Ingénieurs de Metz / Costeam, INRIA Nancy Grand Est, Université de Metz, Ile du Saulcy, 57045 Metz cedex, France

thibaud.monteiro@univ-st-etienne.fr; marie-claude.portmann@loria.fr

\begin{abstract}
Currently enterprises are organizing themselves in "new" structures, alternatively called enterprise networks, Virtual Enterprises, Supply Chains. We are interested in enterprise networks in which decision and information systems are distributed. We are searching for a global performance while controlling the architecture with local bilaterally negotiated co-decisions. We propose an architecture based on multi-agent system and the associated protocols, described by statecharts, to ensure as much as possible a global coherence and the convergence of the decision process. We propose models and tools in order to validate our approach by simulation of the multi-agent system. We employ our model on a particular problem in which enterprises are searching complementary resources (stocks, production capacities, components and/or transport capacities) in order to deal with unexpected orders different from the planned forecasting. The simulation considers parameters of the architecture systems in order to define how many unexpected orders must be treated in parallel the goal is to find a good equilibrium between minimization of answer delay and maximization of efficiency.
\end{abstract}

Keywords: performance evaluation, multi-agent system, distributed decision system, supply chain, cooperation, co-decision, negotiation

\section{Introduction}

Currently the enterprise environment is characterized by globalisation of commercial exchange and diversification of constituent actors. To survive in this environment, enterprises organize themselves in "new” structures, called enterprise networks or supply chains.

The interest in Supply Chain Management (SCM) or enterprise network management is increasing more and more. This is due to new information technologies as well as powerful communication networks such as internet. These technologies speed up the evolution of information and decision systems. This induces a greater diversification 
in the usual partner choices (suppliers and/or customers). To obtain sustainable development, the possession of competitive and robust partners is a strategic stake. In enterprise networks, global performance comes from good coordination between all partners as well as from individual partner performance. As a consequence, techniques and methods to model decision making and coordination mechanisms are very useful. The pertinence and the behaviour of such decision models can be evaluated either by analytical or by simulation approaches. Furthermore it will be necessary to design evaluation methods to measure local and global performance.

In this paper, our goal is to propose a generic architecture for the decision system of such enterprise networks. Information and decision systems are distributed. We assume that the decision system is distributed with only local communication between the decision centres, while maintaining a global coherence of the whole decision system. In order to get a first validation of our model by simulation, we consider a particular application: preparing the answer associated to an unexpected order: by "unexpected" we mean very different from the forecasting plans, which had been previously designed by the partners.

The paper is structured as follows. The first Section presents previous works on enterprise relationships analysis in supply chain structures and justifies the contribution of our work. The second Section presents the industrial context and stakes. The third Section proposes the distributed decision architecture and its protocols, in a very generic environment. The last Section focuses on the validation of the simulation. It contains the particular problem description, the instances generation with several scenarios and the simulation results. We end with some conclusions and perspectives. 


\section{Previous Works}

Many studies focus essentially on enterprise relationships in supply chain structures. Several works are dedicated coordination of two business units (Lavikka et al. 2009). Their goal is to increase financial and operational performance while minimising the global cost and size of the inventories (Turkay et al. 2004) (Camarinha-Matos and Abreu, 2007). In these organisations, the decision making is naturally distributed. Complex processes are then necessary to get an efficiency level similar to centralised decision mechanisms. This is due to myopic and partial view of each enterprise, who cannot evaluate the global impact of its local decisions. Procedures and coordination rules need to be designed to ensure, as much as possible, an efficient management. Another difficulty is to control the large increase of information flow exchanges. Even if it is not easy to measure, global efficiency must be evaluated for distributed supply chains. Performance evaluation must be the main core of any application developed in such distributed systems.

Teti et al. (2006) propose a software tool, based on multi-agent, to control a network of enterprises, associated with a flexible tool for management strategies. They develop an economical evaluation. Ashutosh et al. (2006) develop a local performance evaluation method for suppliers of a given enterprise. Their aim is to optimise supplier selection, but this optimisation is local only. Reiner (2005) illustrates the interest of customer integration in global process in order to maximise the global performance in the supply chain. They propose a dynamic performance evaluation based on simulation where only centralized architectures are considered. Schmitz and Platts (2004) present performance measures for concrete supply chains. They propose an identification method of conceptual frameworks for various configurations of supply chains. Youngui et al. (2004) present a performance evaluation approach which is essentially oriented on the collaboration with suppliers 
based on stock levels. This collaboration is defined between a supplier and a distributor in a two-level supply chain. Zhejun (2008) proposes an economical performance evaluation model in the context of a flexible supply chain.

As illustrated in this rapid review, performance evaluation becomes more and more important for supply chains, when making dimension choices and relationship designs. Nevertheless, literature concerning performance evaluation of cooperative control in distributed decision systems is very poor.

In this paper, we propose a generic distributed decision architecture model based on multi-agent systems. This decision system uses co-decision controlled by negotiation protocols. The proposition is valuated by simulation on a particular decision problem: we must find a solution quickly enough to handle to unexpected orders. The solution is obtained by bilateral negotiation and requires to find: inventory quantities, production capacities, component availability and transport capacities.

\section{Negotiation issue in enterprise network}

In a distributed decision making structure, each entity is considered as an independent decision centre which is capable of modifying the details of its internal processes (i.e. elected to be included in its activity). Those modifications can, with propagation, impact the others entities of the system.

Therefore, in a distributed decision context, it is important to formalize coordination mechanisms able to control this impact. In a global supply chain evaluation, the member-company's internal decisions have to be considered and analysed. This coordination is made by a group of co-decisions based on cooperative behaviours.

Cooperation can be described as a will to act collectively towards a common goal or several compatible goals. In the case of inter-firm industrial flow control, cooperation 
can be considered as the coordination of means of each company composing the network of the supply chain, to produce goods with the final goal of getting equilibrium between cost, quality and delay conflicts. This coordination must create consistent individual decisions and assume their synchronisation.

Decision making becomes necessary after any change of the environment. A change can be either external to the member-company (direct decision maker’s environment), as receiving an unexpected order from a client or occurrence of a problem with a direct provider; or internal, when a new event appears in the company. Here, cooperation includes both collective and distributed decision making, aiming to synchronize actions shared among the different entities. We are in a co-decision context, which intends to coordinate individual actions.

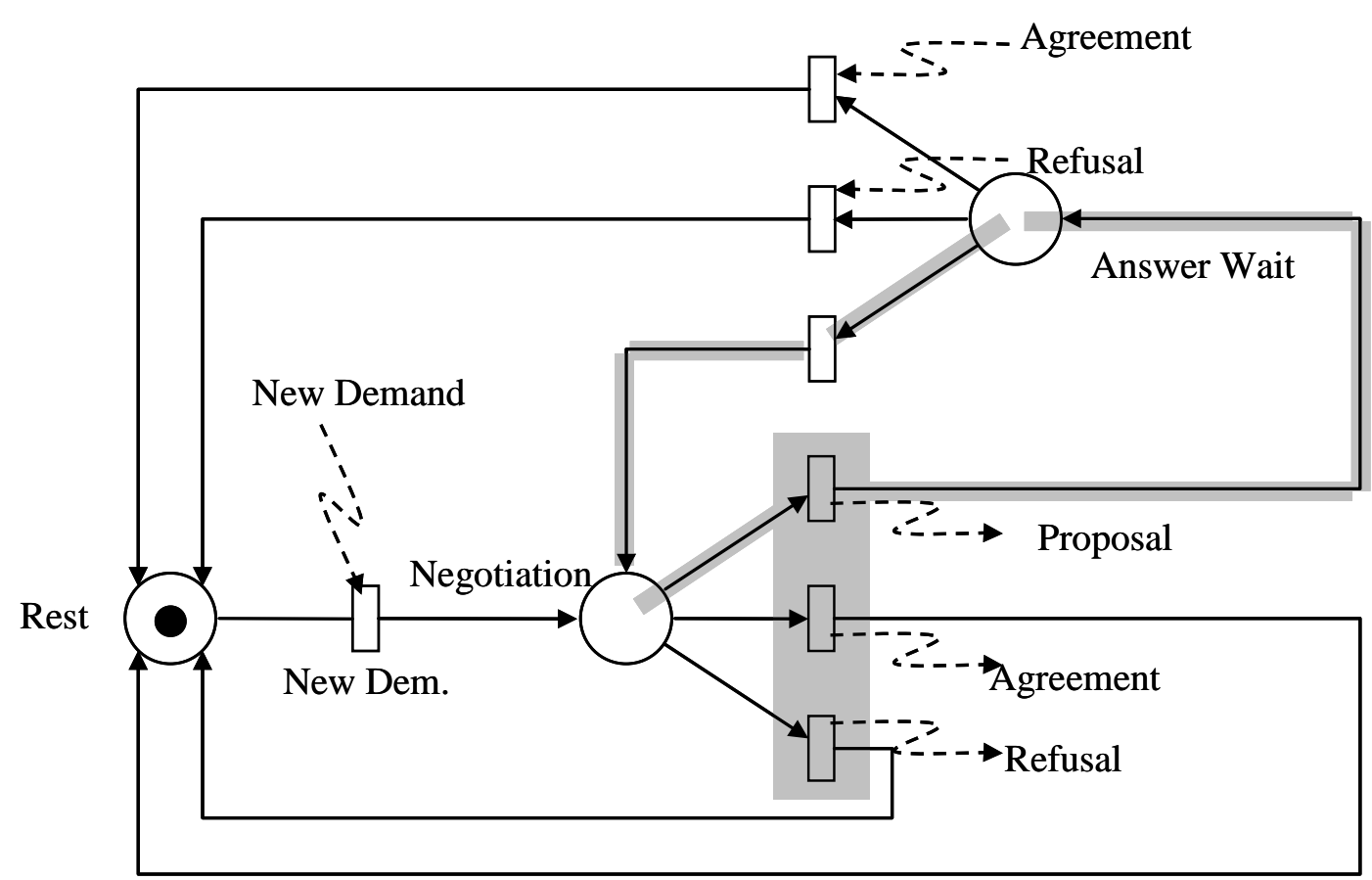

Figure 1. Evolution of negotiation (Monteiro et al. 2004).

The Petri net (Figure 1) illustrates the mechanism of the decision making. When a demand is initially detected, the Rest token, which indicates there is no negotiation, is consumed. The negotiation phase creates three possibilities of firing. Depending on a feasibility study, decision makers can either continue with negotiation by replying 
with a proposal, or stop it by replying with an agreement or a refusal. If he receives a proposal, the second partner will determine his possibility of firing.

Coordination quality is related directly to negotiation quality. Those two points must be studied jointly. The first point is related to the internal decision behaviour. Its efficiency is related to mechanisms used to analysed request feasibility. Efficient Customer Response (ECR) tools are dedicated to this analysis. Presentation of this problem is largely treated in (Pujo and Kieffer 2002). In Figure 1, the new demand analysis allows to choose to fire between the three transitions in conflict (grey zone in Figure 1).

Internal decision performance depends also on negotiation cycle control (grey cycle in Figure 1). As shown by the "answer wait" place of the Petri net, negotiation cycle performance depends also on internal efficiency of the other partners. The second point to be studied is related to interactions induced by inter-firm industrial flow and to network structure. Indeed, when an internal decision cannot be taken, a propagation related to this decision is done. This phenomenon is recursive, and several co-decision cycles could appear.

Figure 2, illustrates this phenomenon of a propagation of one initial co-decision (black arrow, co-decision 1). This propagation has two dimensions. First, it can be in depth when it follows product's macro-bill of material (dotted arrows, co-decision 2 and co-decision 3). Second, it can be in width when it represents multi-supplier strategy or when product's macro-bill of material includes complementary components (dash arrows, co-decision 2'). 




Figure 2. Recursive propagation of negotiation.

This propagation phenomenon can be controlled using specific coordination and/or collaboration mechanisms between entities. In this field, Despotin-Monsarrat (2004) proposes a negotiation model dedicated to coordinate activities between two enterprises. This model is based on a constraint propagation method aiming at harmonizing the decisions of two enterprises of supply chain.

Those two points have to be jointly analysed to evaluate negotiation performance completely. It is important that performance indicators of supply chains are dedicated both to internal decision process (local behaviours) and to the enterprise network (global behaviour). The specificity of our approach is to analyse jointly those points in order to measure simultaneously local and global performances of a supply chain. This approach provides an enterprise with a larger view of the impact of its local decision on the rest of supply chain.

\section{Proposed Approach}

\section{Industrial architecture choice}

In this work, the considered enterprise network is composed by several enterprises which are autonomous in their decision making. Virtual Enterprise (VE) concept has been developed as an improvement of extended enterprise concept. The extended enterprise is presented in (Perrin and Godart 2004). 
VE is an ad hoc organisation that joins core competencies and shares its resources to respond to unexpected business opportunities (Aerts et al. 2002). A comprehensive review of VE concept is given in Wu and Su (2005). Contrary to the extended corporation, the VE characterizes a consortium where each member is totally free for local decision making.

Companies, which compose the supply chain are modelled by decision nodes, such as Virtual Enterprise Nodes (VEN) see (Ouzizi et al. 2006). The enterprise network (Figure 3) is represented as a set of tiers (according to the manufacturing bill of materials and to the propagation of component need), in which each partner, defined as a VEN, is in relation with customers and suppliers on the adjacent tiers. A supplier is in an upper tier than its client. It is assumed that each VEN is only in communication with its adjacent VENs (which induces no circuit in the VENs graph). As a result, each VEN belongs to one tier. This VEN could be as well as a manufacturer, a distribution centre or a carrier. We decide that the upper tier is constituted by carriers (Figure 3). Transport is considered here as service which can be used to move any products between any couples of supply chain partners. Carrier tier is the upper one because it could be called in by all the other network entities. In order to coordinate those decision centres, negotiation and data exchange mechanisms are integrated in the architecture. The relationship, which controls two direct partners of the network is based on a win-win collaboration policy (Ouzizi et al. 2003). That policy aims at maximising individual partners' benefits in a global agreement.

This enterprise network is modelled as a multi-agent system, in which the agents use cooperative negotiation to establish a global consistent coordination. 


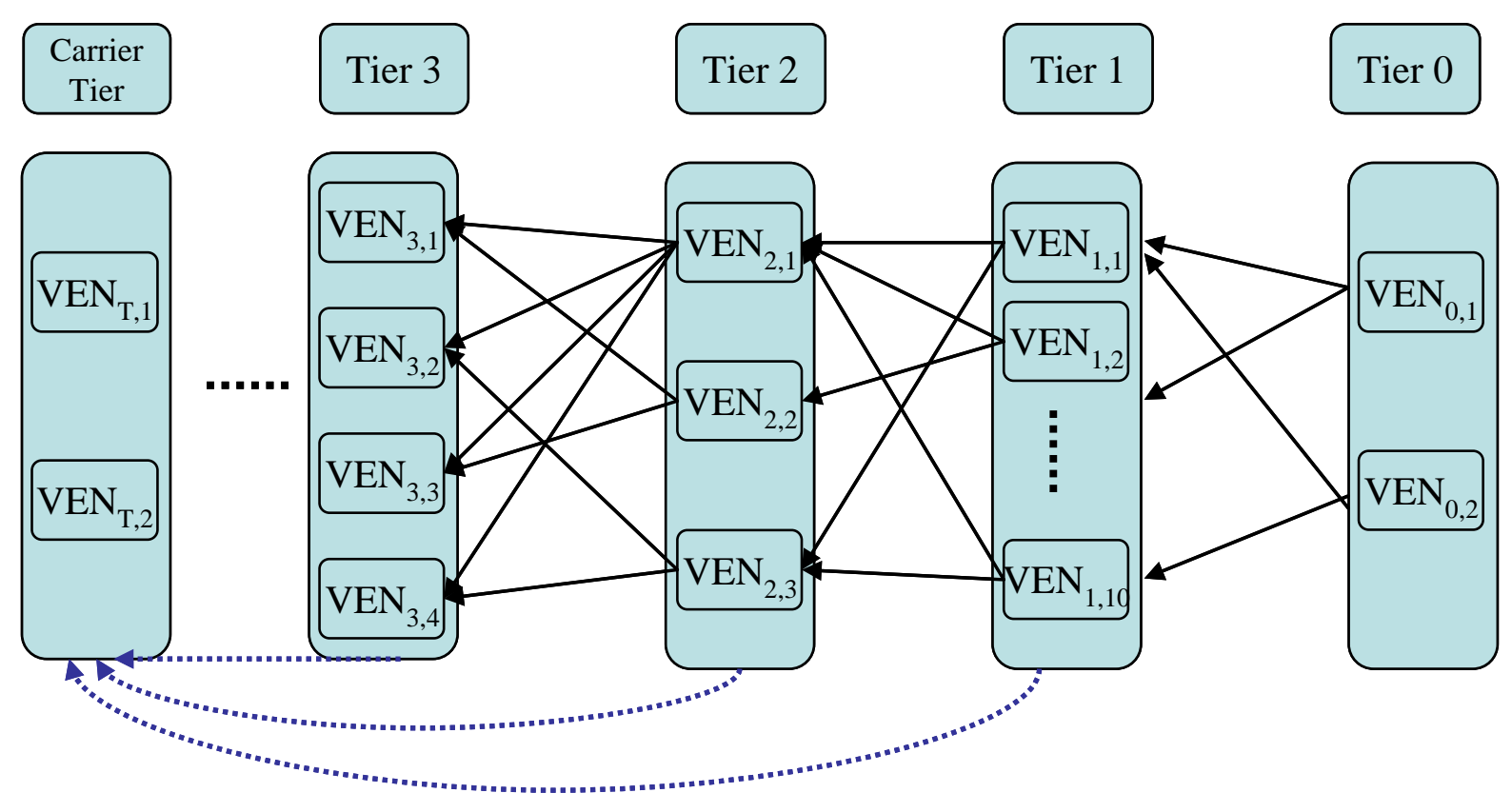

Figure 3. Model of a network of enterprises.

Generic multi-agent architecture for supply chain management and evaluation

The VEN is the basic component of our architecture. Relationships between two chain partners (suppliers and customers) are located in adjacent tiers. Each company is able to take its own decision without external manager control of the other company. Thus, the architecture is totally distributed.

In our approach, we model VENs using multi-agent architecture. An agent is a combination of reactive software entity and human decision actor, with its own environment and decision making tools. To improve its performance, an agent collaborates with the other entities existing in its environment (Luck et al. 2004). The VEN is a meta-agent, which is composed with three types of software agents. They collaborate with each other to achieve the company goals (Figure 4):

- The Negotiation Seller Agent manages and negotiates sales;

- The Negotiation Buyer Agent manages and negotiates purchases operation;

- The Negotiation Planner Agent manages production plans.

Each of these agents is a simple reflex agent (Luck et al. 2004). Even if agents use decision making tools based on operational research models and tools, induced actions are predetermined. Agent activation results from a change in its direct 
environment. When several requests came in the same time VEN will initiate, for example, as many Negotiation Seller Agents as necessary to take into account those requests. All those agents work simultaneously. In that situation, we are in presence of parallel demand processing. Those meta-agents are connected in our multi-agent architecture. Each agent is equipped with environment communication abilities regrouped in a communication platform.

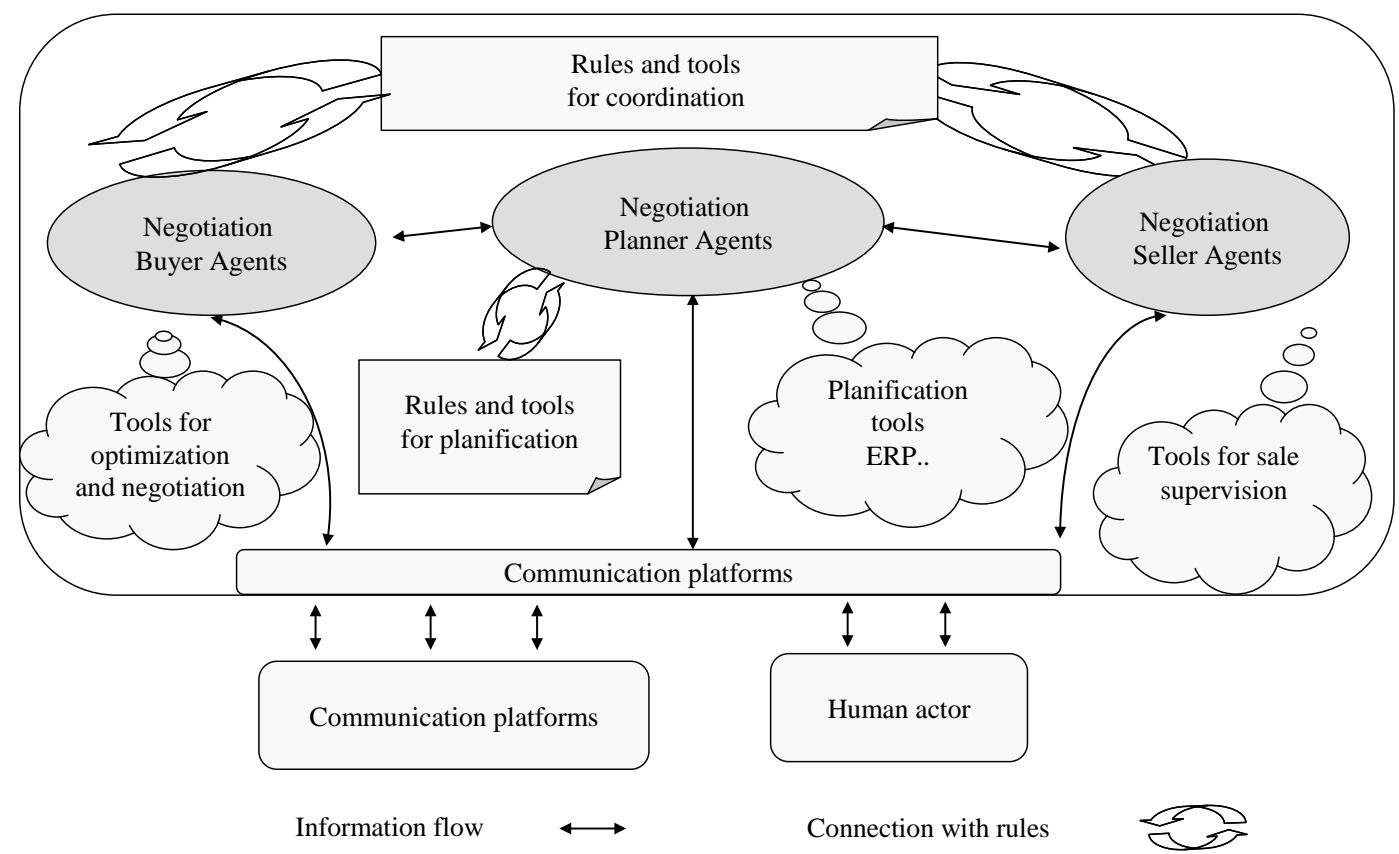

Figure 4. Internal VEN structure.

The Negotiation Seller Agent (NSA)

The Negotiation Seller Agent manages and negotiates sales. NSA contacts directly internal Negotiation Planner Agents and several external Negotiation Buyer Agents (its customers). The main function of this agent pattern is the management of VEN sale processes. When a request occurs, one specific NSA is activated. It can reply directly with a proposal, with an agreement or with a refusal. If necessary, it can propagate this request to other agents before making a decision. If two requests occur during the same time period, two specific NSA are activated. Those agents share enterprise resources. Conflicts can appear between those two decision processes. Figure 5 illustrate, with a statechart, the internal behaviour of NSA. This behaviour is 
voluntarily generic. It is used also to describe internal behaviours of NPA and NBA. Indeed, even if main function and goal are different, internal behaviours are similar. NSA is activated by a message, which comes from an external or an internal agent. When activated, NSA manages all required specific actions. Decision making is based on its own databases and its own sale tools. Activation messages, called $a$ in Figure 5, are:

- New product request from client (external NBA);

- Modification request of a previous agreement. Modifications could come from a client or from an internal NPA;

- New product proposal from an internal NPA.

The Negotiation Planner Agent (NPA)

The Negotiation Planner Agent provides forecasted planning and finished product availability. The main function of this agent pattern is to manage and negotiate VEN production planning. If necessary, it contacts directly the two other VEN agents. It uses either planning software pre-existing in the company or imposes the design of planning rules. This agent is activated in the same way as NSA. Activation messages, also called $a$ in Figure 5, are:

- New production planning request from a NSA;

- Modification request of a previous planning agreement. Modifications could come from an internal NSA or NBA.

The Negotiation Buyer Agent (NBA)

The Negotiation Buyer Agent manages and negotiates purchase operations. NBA contacts negotiation planning agents and several external sale agents directly (its suppliers). The main function of this agent pattern is to manage VEN external resource acquisition. Resources could be components (example: raw materials) or services (example: transport or subcontracting). Messages that activate those agents are (also called $a$ in Figure 5):

- New resource request from a NPA; 
- Modification request of a previous supply agreement. Modifications could come from an internal NPA or an external NSA.

For the decision making NBA can use its own data bases and several supply tools. For example, some authors have designed mathematical linear models and proposed tools for decision making in various NBA problems such as, supplier selection (Khouider et al. 2005), carrier selection (Khouider et al. 2006a), palliative supplier research (Khouider et al. 2006b) or consistent supply chain plans negotiation (Ouzizi 2005)

\section{VEN internal treatment}

As we said previously, the three negotiator agents, buyer (NBA), planner (NPA) and seller (NSA), have a similar internal behaviour. Statechart modelling helps understanding the negotiation process within agents. The agent behaviour is illustrated with a generic statechart (Figure 5) where only events and internal processes differ between each other.

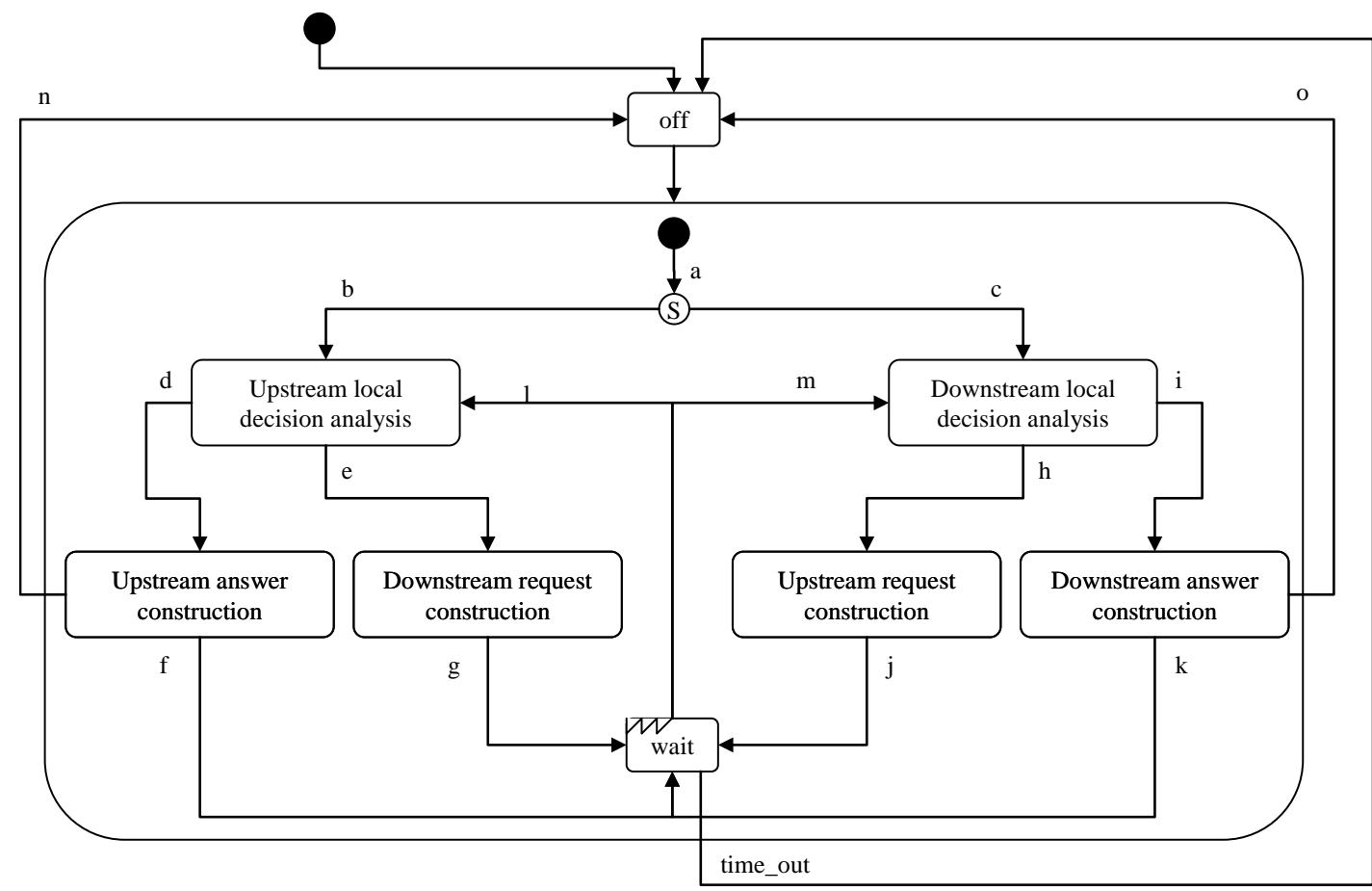

Figure 5. Statechart of the generic behaviour of an agent.

Different messages used by the agents are shown in Table 1. Messages correspond to different state of negotiation with downstream or upstream agents. The first line (table 
head) identifies agents that receive messages. R_NPA denotes a request coming from a NPA. A_NSA denotes an answer coming from a NSA. Two local decision situations exist. If NPA has all the information needed to make decision, then a local decision is possible. If not, then a local decision is not possible and the agent has to propagate the request. The following is a set of events and messages which can modify agent state (Table1):

\begin{tabular}{|l|l|l|l|l|}
\hline message & NBA & NPA & NSA & comments \\
\hline $\mathrm{a}-\leftarrow$ & R_NPA & R_NSA & R_NBA & Request which makes agent to wake \\
& R_NSA & R_NBA & R_NPA & up \\
\hline b & R_NPA & R_NSA & R_NBA & Upstream request \\
\hline c & R_NSA & R_NBA & R_NPA & Downstream request \\
\hline d & \multicolumn{2}{|l|}{ Local decision possible } & \\
\hline e & \multicolumn{2}{|l|}{ Local decision impossible } & \\
\hline $\mathrm{f}-\rightarrow$ & A_NBA & A_NPA & A_NSA & Proposal to upstream \\
\hline $\mathrm{g}-\rightarrow$ & R_NBA & R_NPA & R_NSA & Request propagation to downstream \\
\hline $\mathrm{h}$ & \multicolumn{5}{|l|}{ Local decision impossible } & \\
\hline $\mathrm{i}$ & Local decision possible & \\
\hline $\mathrm{j}-\rightarrow$ & R_NBA & R_NPA & R_NSA & Request propagation to upstream \\
\hline $\mathrm{k}-\rightarrow$ & A_NBA & A_NPA & A_NSA & Proposal to downstream \\
\hline $\mathrm{l}-\leftarrow$ & A_NSA & A_NBA & A_NPA & Downstream answer \\
\hline $\mathrm{m}-\leftarrow$ & A_NPA & A_NSA & A_NBA & Upstream answer \\
\hline $\mathrm{n}-\rightarrow$ & A_NBA & A_NPA & A_NSA & Answer (ok, /ok) to upstream \\
\hline o $-\rightarrow$ & A_NBA & A_NPA & A_NSA & Answer (ok, /ok) to downstream \\
\hline
\end{tabular}

Table 1. Messages and internal events.

External flows for a cooperative decision

An example of treatment of a new command is presented Figure 6. We consider a company VEN 2.1 with its client VEN 1.1 and its two providers VEN 3.1 and 3.2 (see Figure 3). 


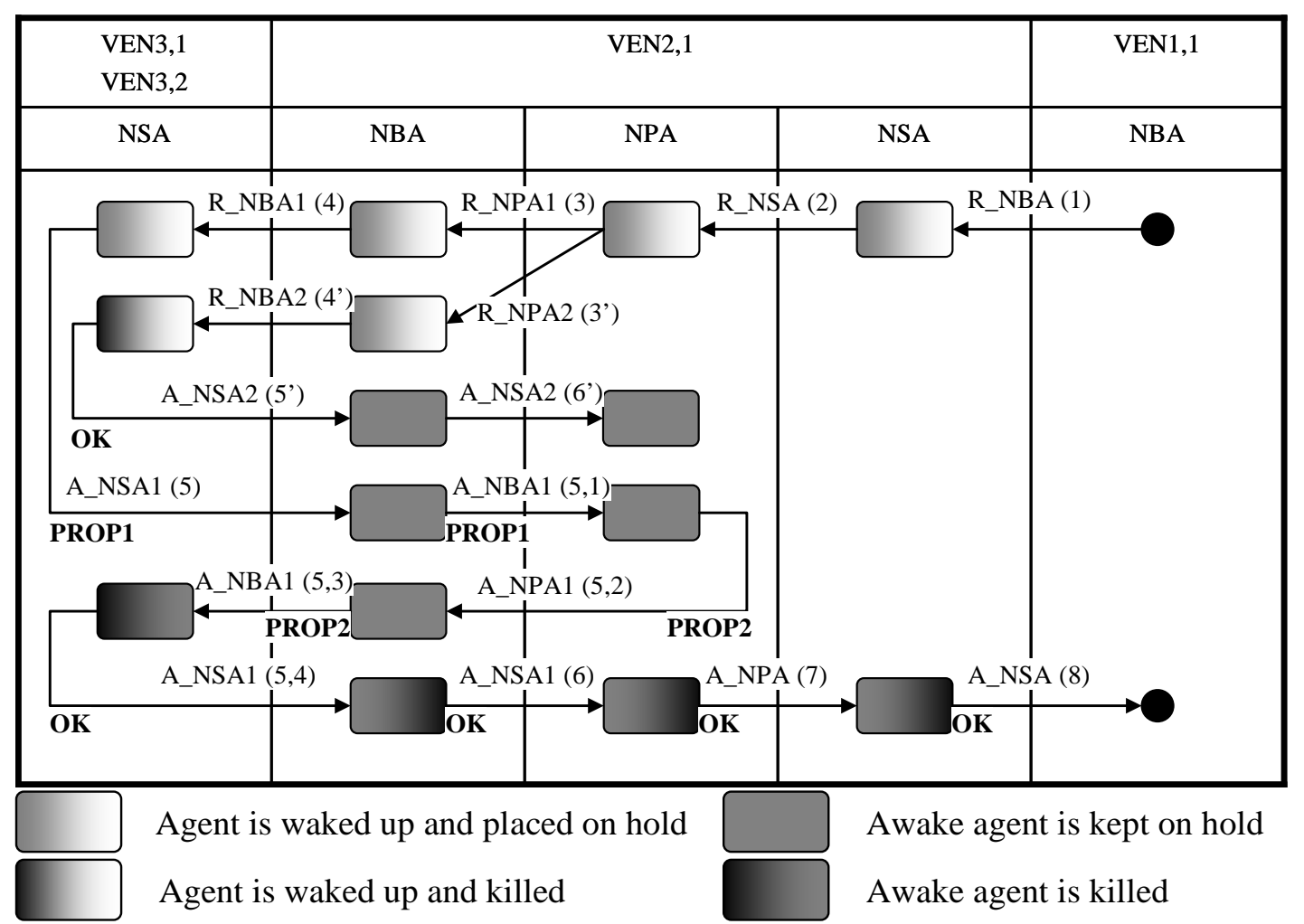

Figure 6. Swimlane illustrating a global view of cooperative decision.

Cooperative decision starts with the receipt of message 1. The Negotiator Buyer Agent of VEN 1.1 sends a demand of product to VEN 2.1. This message wakes up the Negotiator Seller Agent of VEN 2.1 and the NBA of VEN 1.1 start waiting. The demand concerns one or more products with indication of quantities, due dates, cost, etc. In this example, The NSA cannot find a solution by itself (i.e. insufficient inventory, lack of information, etc.). At this point, no local decision can be made. NSA sends a request to its Negotiator Planner Agent (message 2). This message wakes NPA up and NSA start waiting. Thus, the first co-decision initiated with message 1 is propagated in depth with messages 2,3 and 4 , and is propagated in width with message 3'. Performance of this cooperative decision is related to those propagations. For example, NPA (VEN2,1) waken by message 2 has to obtain two agreement messages (6 and 6') before local decision making. In this example, the first co-decision generates five other co-decisions and requires fourteen messages. 


\section{Illustration on some co-decision problems linking to supply chain control}

In many networks, each business unit or entity plans its operation locally. Several reasons support this approach. Demand and supply of information is widely spread within the network. This information is continually changing as the business environment is stressed by many internal and external factors. The quantity of information to deal with is still too large in some instances to make a feasible centralized planning process. However, this decentralisation raises some interesting questions. They emerge from the difficulty to synchronize the planning and coordinating decisions without an extensive share of information that would be found in a centralized approach. This section addresses this issue though the proposed distributed approach, based on multi-agent paradigm.

The first part deals with cooperative tactical planning by proposing a method to consider contingency in supply chain. This is a middle term problem.

The second part of this section describes a short term problem with an approach to manage unexpected orders. Even if it is a short term problem, its design is a strategic problem that could be solved with a simulation approach.

Unexpected order satisfaction is our main contribution in this paper. So, cooperative tactical planning is presented in this paper in order to illustrate its connection with unexpected order satisfaction problem. Cooperative tactical planning is more detailed in (Ouzizi 2005).

\section{Cooperative tactical planning}

Each VEN of the first tier collects information about future sales from the customers, generally with an estimation of uncertainty. The forecasts are transmitted to all the VENs of the supply chain. It is assumed on one hand that agreements are signed between VENs of the first tier and customers, and on other hand between partners of the SC. Thus, it is assumed that information is always shared truthfully (trusted 
relationships) (Gavirneni et al. 1999, Cachon and Lariviere 2001). On the basis of forecasting data and contracts established, each VEN makes its planning. In the event of unforeseen production problems of a VEN, or of forecasting change, it must commit with its current customer and supplier VENs, so that they try to overcome the problem collectively, which ensures the continuity of the production and global nonstop of the manufacturing chains.

Using a rolling horizon (Ouzizi et al. 2003), the VENs do the planning with new forecasting (Figure 7). It is assumed that, (1) in the last unit of time, planning over the supply chain are negotiated and coherent, (2) at the beginning of the next period of planning, each VEN of the first level must readjust its planning according to the demands variation for finished product, or of possible risks that can occur during the period.

Thus, the consequences are:

- To correct forecasts of finished products from the period 1 to T-1 (these forecasts are the same corresponding to periods 2 to $\mathrm{T}$ with corrections)

- To add a new forecast for the period T

- To update inventories of all upstream and downstream components of the supply chain.

Forcastings and

Contracts

$$
\mathrm{FC}_{\text {old }}
$$

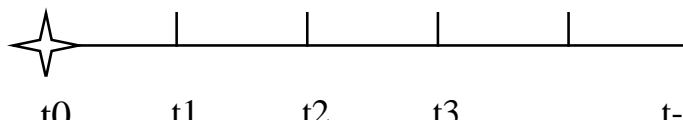

$\mathrm{FC}_{\text {new }}$

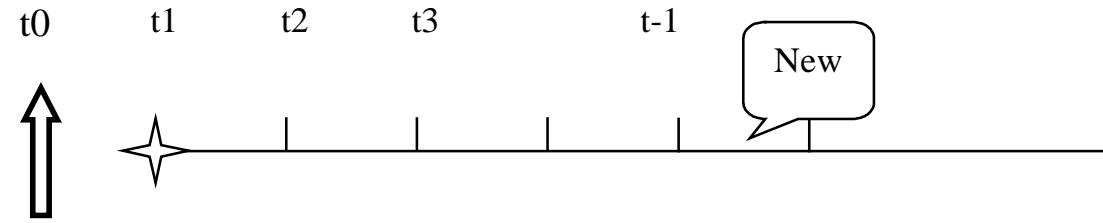

$\mathrm{t1} \quad \mathrm{t} 2$

$\mathrm{t}$

Figure 7. Rolling horizon for planning.

The problem for each VEN is to determine if it is sufficient to add one period for the planning in order to cope with variations or if it is necessary to increase or decrease 
the previous planning so as to find coherent and negotiable planning (Roy et al. 2004).

In theory, each VEN is faced with internal constraints which relate to its capacity limits, and with external constraints which relate to both:

- The customer VENs. These require products that have for example, minimal delays or low costs,

- The supplier VENs. With similar constraints of lead times, costs, etc.

Two VEN scenarios are possible in relationship to the VEN capability to make or not a request. The first scenario is when there is no problem of consistency. In this case, the VEN is only used to propagate the needs of the client to supplier requests. The second scenario is when a local problem occurs. In this case, it is necessary to initiate a negotiation process. To cope with those issues and in the case of unexpected orders, the following section presents the problem and details a method to solve it. The following section presents the issues related to these two scenarios, as well as a solution method. It focuses on the case of unexpected orders.

\section{The problem of unexpected order satisfaction}

Description of the decision problem

Unexpected orders (Kouider 2008) are linked to firm orders which differ by the plans that were established by the process of middle-term decision. The difference in firm order could result from two factors. First, the firm order does not respect the established plan in relation to quantities or delays. Second, an urgent non-planned order occurs. Even if those situations are singular, unexpected orders are still the principal cause of supply chain performance deterioration. The bullwhip effect is one of the most known consequences of these situations (Moyaux and D’Amours 2003). In case of a new order arrival, i.e. a customer sends a planed (or not) product order to the company, the company needs to perform some operations before introducing the 
new order in the production planning such as transportation, product and purchase plans (Figure 8). To satisfy the order, ones need to verify with existing inventories of finished products. If more production is required the planning must be modified and the company has to reconsider two of its capacity aspects. First, the company needs to verify the availability of inside capacities, such as product, reception and loading capacities. Second, the company needs to verify the availability of outside capacities, such as component and transportation capacities.

To manage all these capacities constraints, we use the modelled VEN presented in Figure 4.

The proposed management agents can eventually use decision making tools that already exist in the company.

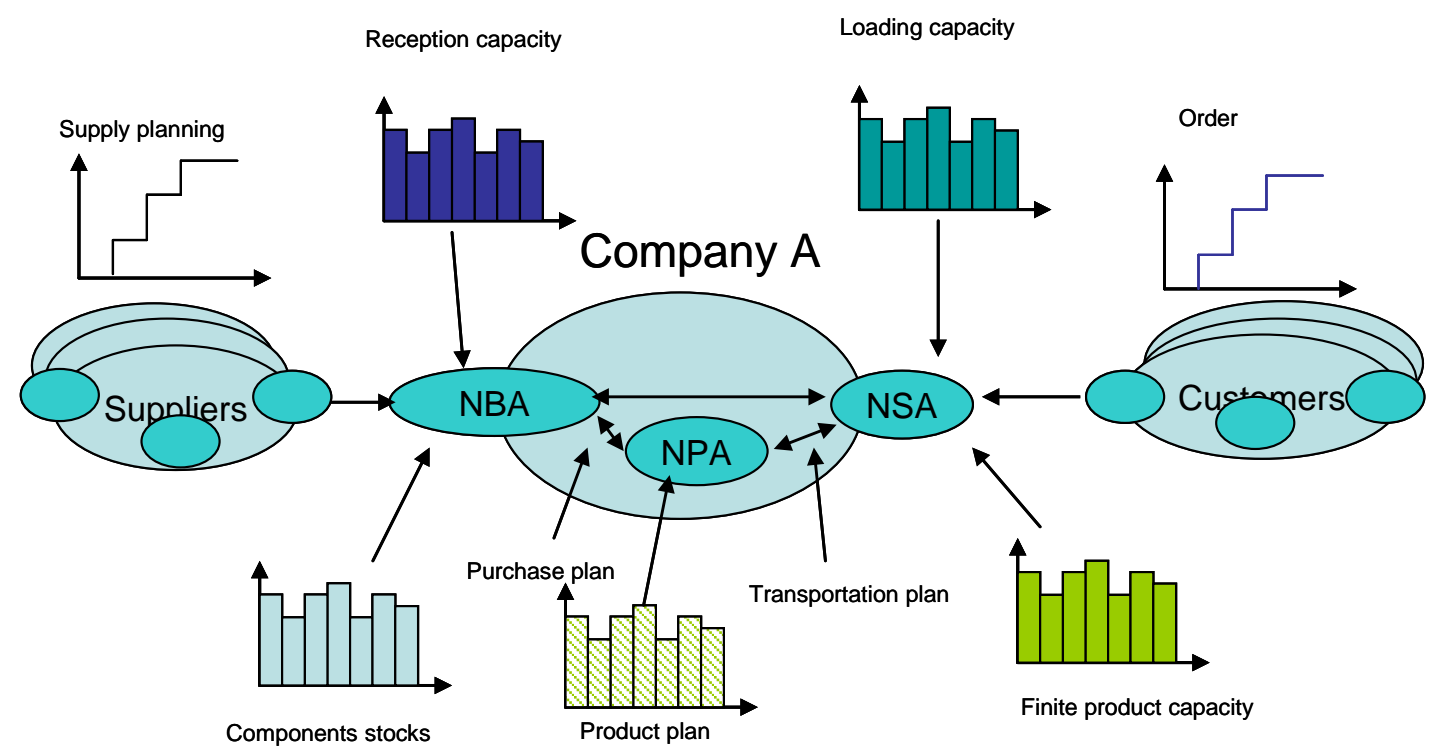

Figure 8. Decision problem.

Integration of unexpected order

We present typical examples of decision problem. For decision making, it is possible to analyse the integration of unexpected order with only internal process or, if it is necessary, with external propagation requests (Figure 9).

We present here two categories of external problems: a component supply problem and a problem that relates to find and organize supply or distribution transport 
(transport problem). In the component problem case, an arrival of new order induces new production and insufficient quantities of components are in inventories. In the transport problem case, the company has to deliver or transport products to the customers.

We take the example where the company needs some components and transports in order to deliver the order. Therefore, the ordered quantity is insufficient in the product inventories, even though there is enough production capacity (component problem). The internal transportation capacities are insufficient (transport problem). The company contacts its suppliers and transportation capacity suppliers (carriers) to provide the missing components and to carry, totally or partially, the ordered quantity to the customer (Figure 9).

The first co-decision, identified by message 1 (Customer order) and 12 (Confirmation of order) in Figure 9, requires five other co-decisions. The first induced co-decision concerns an internal negotiation between NSA and NPA with message 2 (NSA production demand) and message 11 (NPA confirmation of demand). This codecision generates, by propagation in width, two other co-decisions. One propagation concerns the component search (message 3 and 6). The other propagations concern the search for finish products transport (message 7 and 10). Those two last internal negotiations between NPA and NBA are propagated in depth with two external negotiations between NBA and suppliers’ NSA (message 4/5 and 8/9). 


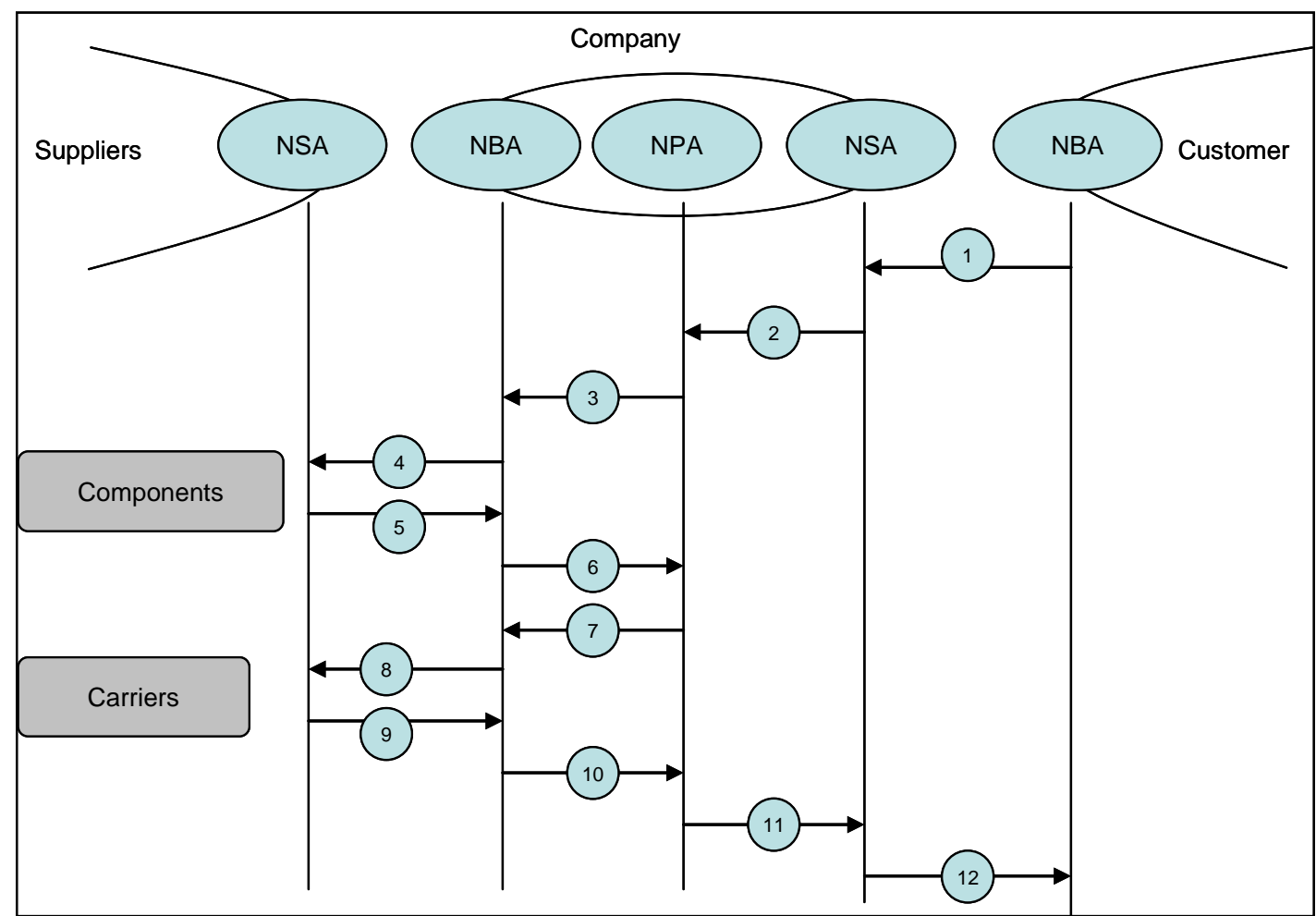

1: Customer order

7: NPA transport demand

2: NSA production demand

8: NBA transport demand

3: NPA transport and component demand

9: Carrier answers

4: NBA components demand

10: NBA confirmation of demand

5: Supplier answers

11: NPA confirmation of demand

6: NBA confirmation demand

12: Confirmation of order

Figure 9. Example of a resolution mechanism.

\section{Design of cooperation mechanism}

In order to efficiently manage those co-decisions, it is important to set up specific

parameters that are related to cooperation mechanisms. Many approaches exist to deal with the supply chain management. Those approaches aim to ensure decision

coherence among the network and to allow an efficient collaboration to guaranty the supply chain survival and stability. In order to analyze the negotiation performance in such a system (Khouider et al., 2008), we propose to use the modelling framework as a simulation tool.

Some specific parameters need to be defined to be able to evaluate the supply chain performance. Those parameters can be classified in two different fields: the network architecture and the negotiation process. From the point of view of the architecture, 
the network nature (number and size of tiers) or the supply strategy (mono or multi sourcing) are relevant. From the point of view of the negotiation process, the maximum number of exchange flows for a negotiation, or the number of proposition and scenario which are simultaneously treated, are analysed.

The expected measures are linked to generated information flows and to the success of cooperation and coordination. Finally, the allocated time to achieve decision is also taken into account (Figure 10). Indeed, it is important to have decisional parameter for an agile supply chain.

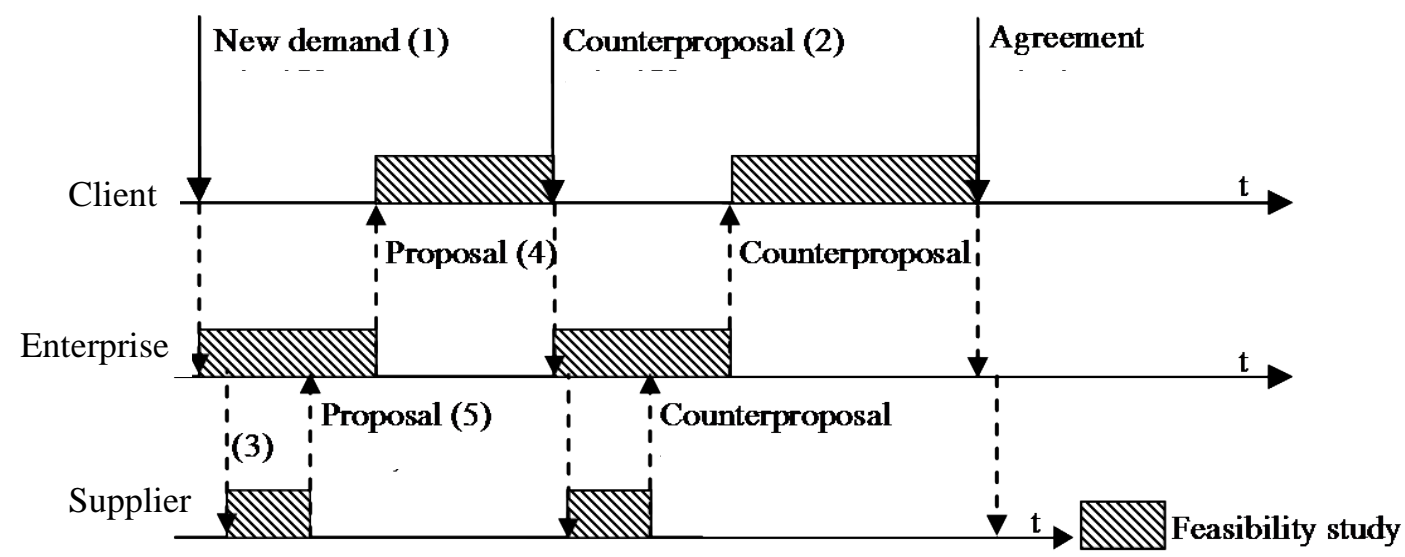

Figure 10. Allocated time in order generation based on negotiation.

Example of simulation for multi-negotiation parameter

In order to illustrate the cooperation design based on simulation, we specifically look at the negotiation setting. In this example, we search to define negotiation parameter of the VEN 2.1 (greyed in Figure 11) for its Negotiator Seller Agents. We assume in this simulation that the product used is bought by ten different clients (VEN 1.1 to VEN 1.10). Therefore, a maximum of ten unexpected orders could occur for the same period. The product is composed by two different components, and each component is supplied by two suppliers (VEN 3.1 to VEN 3.4). 


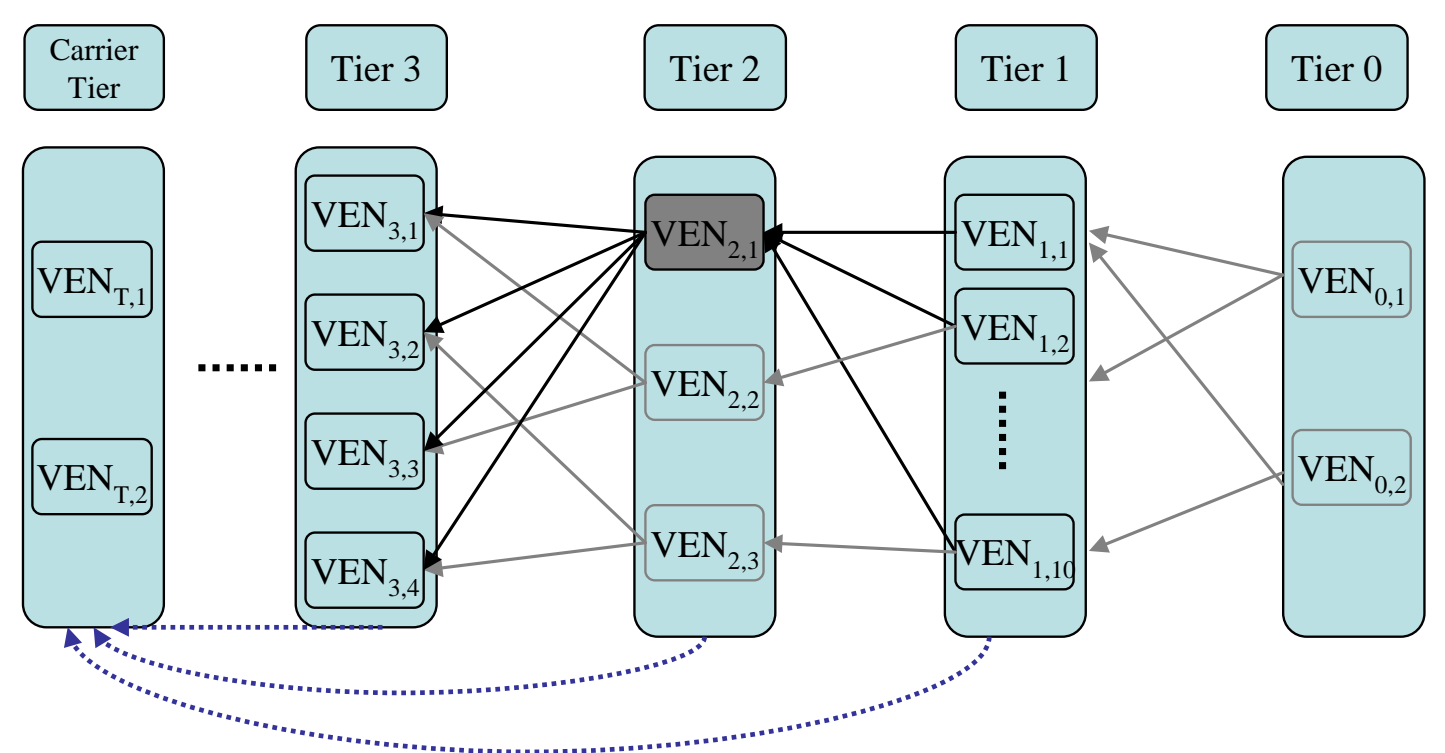

Figure 11. Network of enterprises used in the simulation.

Face to clients' requests, we compare two possible strategies that depend on how the orders are treated. First, orders are considered sequentially and separately. This way allows us to avoid resource reservation conflicts. This strategy guaranties no refusal errors. Indeed, in case of rejection due to incompatibility of a production plan, raw material or component supply, we are sure that this analysis is always well-founded. However, separately analysis could cause the loss of some orders due to the increase in delay of the last orders. Moreover, the results (acceptations or refusals) depend on the sequence analysis of the orders. The second strategy is to treat some orders at the same time. This allows us to take simultaneously into account $\mathrm{N}$ numbers of orders. The propagations that correspond to each order are independent and are treated by distinct agents. To prevent simultaneous use of the same resources, the information system includes both definitive and temporal reservations (as it is the case for classical “online” reservation systems). When one negotiation ends, another one can start to be analyzed. An acceptation or refusal sending ends the negotiation. This second strategy allows parallel analysis of orders and therefore provides smaller waiting times than the first strategy. In the second strategy, the response time creates thus less order lost. However, this strategy has a bigger risk with refusing an order, 
due to parallel temporal resource reservations. This same order could be accepted with a valid analysis as in the first strategy. In this second strategy, it is important to analyze the relations between the maximum number $(\mathrm{N})$ of simultaneous treated orders, the response time and the decision pertinence.

\section{Instances generation and simulation}

Khouider (2008) presents a complete simulation project on both strategies, realized on the unexpected order problem. Here, we look at the enterprise network problem (figure 11). We consider the case where the bill of material for the product requires all the partners of the supply chain and where associated needs of capacities have already been generated. An initial state has also been generated for the resource availability with various scenarios which depend on the importance of idle capacities. Orders are also randomly generated with identical values among all simulations. A set of experiments have been realized with $\mathrm{N}=1$ (first strategy) and $\mathrm{N}$ varying from 2 to 6 (second strategy). In the simulations, the decisions of VEN2.1, our studied node, are made using linear programming tools, while answers of other nodes are randomly generated.

From the point of view of response time (Figure 12), the simulation results show a direct relation between negotiation parallelization $(\mathrm{N})$ and treatment quickness. It results that negotiation parallelization is a crucial parameter for negotiation agility. There is, nevertheless, a limit on this parallelization impact on the response time reduction (asymptote at around $\mathrm{N}=4$, Figure 12 ). 


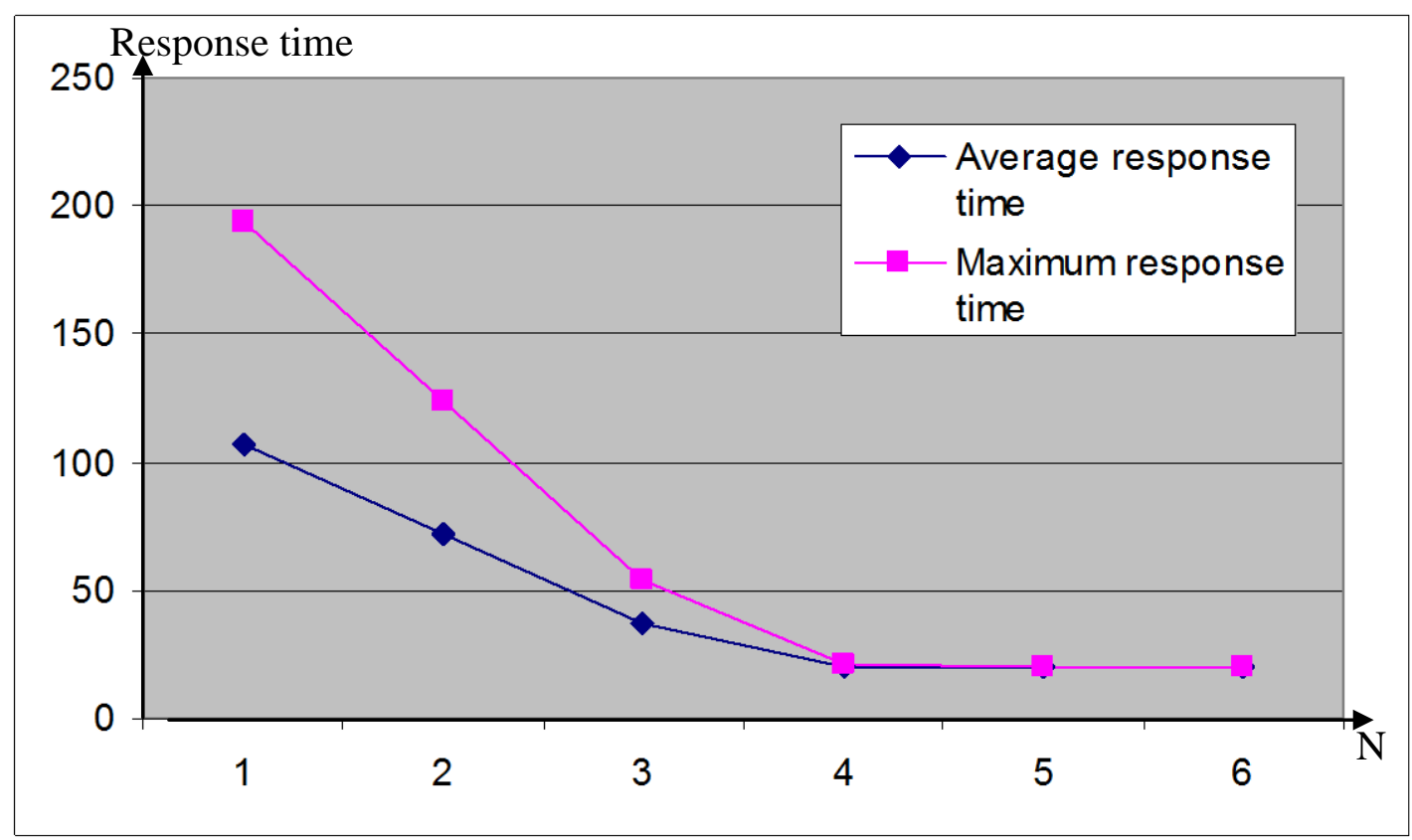

Figure 12. Time to reply analysis.

From the point of view of lost orders, as shown in Figure 13, a relation also exists, between the negotiation parallelization and loss of orders. This loss is due to two factors. First, a loss of order can result from an over delay response (response time in Figure 13). The impact of this factor decreases with parallelization growing. Second, the lost order could be caused by an over temporal reservation (false lack of resources in Figure 13). In this case, the impact of this factor increases with parallelization growing. It exists an equilibrium between those two factors which defines an optimal set of parameters. In the example presented in Figure 12, four parallel co-decisions give the best performance. To efficiently manage negotiation in the supply chain, a maximum of four negotiator agents should be set up in VEN 2.1. 


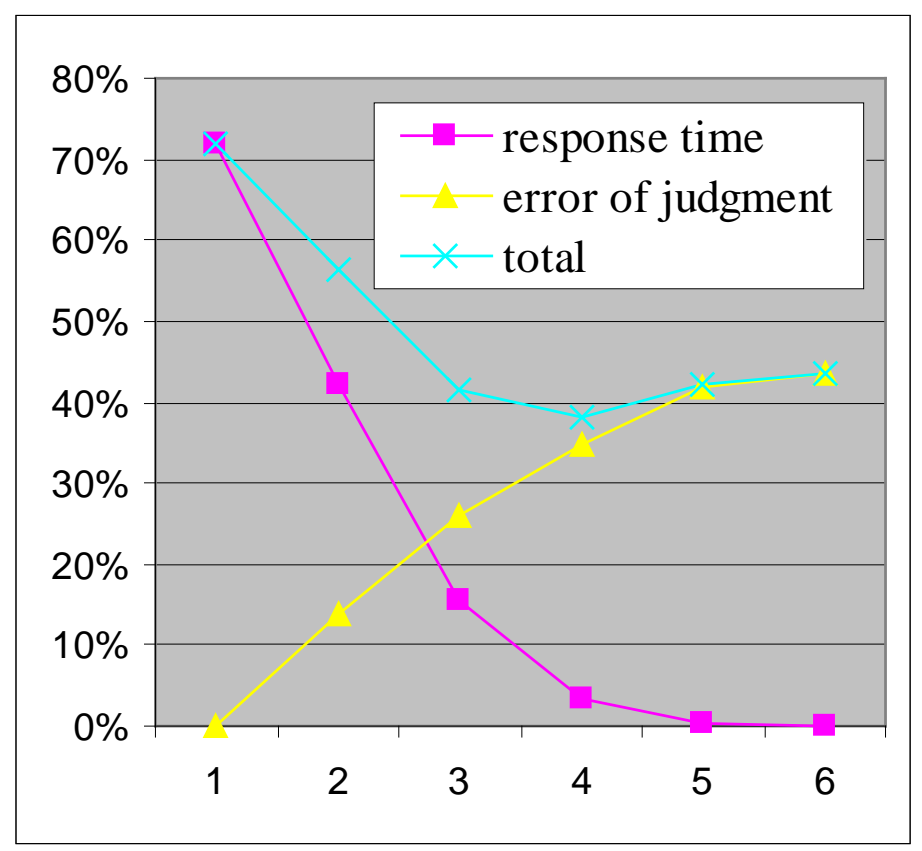

Figure 13. Lost of orders analysis.

\section{Conclusion}

The evaluation of the negotiation performance inside a supply chain is becoming more and more complex and requires better strategy of management. In this paper, we propose a co-decision distributed architecture system based on multi-agents. The system can be effectively used by supply chain managers. We employed this architecture on a particular negotiation problem in order to simulate negotiation protocols and to consider corresponding parameters in the case of parallel negotiation. We illustrated how we can consider in parallel several demands in order to improve negotiation performance and how to limit the number of adequate negotiators in order to assume the negotiation convergence. Our aim is to give performance indicators, by analyzing the behaviour of this decision architecture, in order to help the enterprises to collaborate efficiently using this negotiation model. The obtained results show clearly that the use of parallel negotiations improves convergence and reduces the negotiation volumes in a given configuration of a distributed supply chain. In the near future, negotiation mechanism analysis would be extended to consider other parameters. For example, in order to increase the chance to find a solution, 
different planning scenarios could be analysed for one demand. All those scenarios are treated in parallel, probably inducing similar problems to those found in parallel negotiations. Another way to reduce refusals in a parallel strategy is overbooking policy, however with this policy, negotiators could accept a demand that they are not able to satisfy. This policy has to be configured with care. All these new negotiation mechanisms and associated parameters aim to find a good equilibrium between the quality of the co-decisions and the allocated time to keep agility in enterprise networks.

Acknowledgements: A part of this paper has been presented at the conference MOSIM'08 organized by S. Lamouri and A. Thomas, held in Marsh 2008 at Paris, France.

\section{References}

Aerts A.T.M., Szirbik N.B., \& Goossenaerts J.B.M. (2002), “A flexible, agent-based ICT architecture for virtual enterprises” Computers in Industry, 49, 311-327.

Ashutosh Sarkara and Pratap K.J. Mohapatra (2006), "Evaluation of supplier capability and performance: A method for supply base reduction”, Journal of Purchasing \& Supply Management 12 (2006) 148-163.

Cachon, G.P., Lariviere, M.A. (2001), Contracting to assure supply: how to share demand forecasts in a supply chain. Management Science, 47(5), 629-647.

Camarinha-Matos, L. M., Abreu, A. (2007). Performance indicators for collaborative networks based on collaboration benefits, Production Planning \& Control, 1366-5871, Volume 18, Issue 7, 2007, Pages 592 - 609.

Despotin-Monsarrat, E. (2004), “Aide à la décision pour une coopération interentreprise dans le cadre de la production à la commande”. Thèse de doctorat, Laboratoire d'Analyse et d'Architecture des Systèmes du CNRS, 2004.

Gavirneni, S., Kapuscinski, S.R., Tayur, S. (1999), Value of information in capacitated supply chains. Management Science, 45(11), 16-24.

Khouider S. (2008), Outils d'aide à la décision pour la prise de commandes imprévues, Ph. D. Thesis, Université de Metz, France.

Khouider, S., Monteiro, T. \& Portmann, M-C. (2005), Suppliers searching tool in cooperative supply-chain management, in CORS 2005 47e congrès annuel de la Canadian Operational Research Society, Halifax, Canada, mai 2005.

Khouider, S., Monteiro, T. \& Portmann, M-C. (2006a), Gestion collaborative et distribuée des approvisionnements intégrant le transport, in CIFA06 Conférence Internationale francophone d'Automatique, Bordeaux, France, mai 2006, CD-Rom.

Khouider, S., Monteiro, T. \& Portmann, M-C. (2006b), Collaborative model for customer request ordering: research and selection of palliative suppliers, in Proceedings of International Conference on Information Systems, Logistics and Supply Chain, Lyon, France, mai 2006, pp. 668-677, ISBN 2-930294-183. 
Khouider, S., Monteiro, T. \& Portmann, M-C. (2008), Cadre de modélisation pour évaluation par simulation des mécanismes de négociation dans les entreprises en réseau, in: MOSIM08 the $7^{e}$ Conférence Francophone de Modélisation et Simulation, Paris, France, mars 2008, Éditions Tec\&Doc - Lavoisier, pp. 667676, ISBN 978-2-7430-1057-7.

Lavikka R., Smeds R. \& Jaatinen M. (2009), Coordinating the service process of two business units towards a joint customer, Production Planning \& Control, Volume 20, Issue 2 March 2009, pages 135 - 146.

Luck, M., Mc. Burney, P., Preist, C. (2004), A Manifesto for Agent Technology: Towards Next Generation Computing, Autonomous Agents and Multi-Agent Systems, Vol. 9, p. 203-252.

Monteiro T., Ladet P. \& Bouchriha H. (2004), Multi-criteria negotiation for a distributed control of a client/provider relationship, Journal of Decision System, n¹/2004, volume 13, p. 63-89, 2004.

Moyaux, T., D’Amours S. (2003), Multi-Agent Coordination Based on Tokens: Reduction of the Bullwhip Effect in a Forest Supply Chain, Proceedings of AAMAS'03, Melbourne, Australia.

Ouzizi, L. (2005), Planification de la production par co-décision et négociation de l'entreprise virtuelle, Ph. D. Thesis, Université de Metz, France.

Ouzizi, L., Anciaux, D., Portmann, M.C., \& Vernadat, F. (2003). A model for cooperative planning using a virtual enterprise. Proceedings of the $6^{\text {th }}$ international conference on Industrial Engineering and Production Management, Porto, Portugal.

Ouzizi, L., Anciaux, D., Portmann M.C. \& Vernadat F. (2006), A model for cooperative planning within a virtual enterprise, International Journal of Computer Integrated Manufacturing, Volume 19, Number 3, pp. 197-209(13).

Perrin, O., Godart, C. (2004), “A model to support collaborative work in virtual enterprises”, Data \& Knowledge Engineering, 50, 63-86.

Pujo, P., Keiffer J.P. (2002), “Méthodes du pilotage des systèmes de production”, éditions Hermès Lavoisier.

Reiner G. (2005), "Customer-oriented improvement and evaluation of supply chain processes supported by simulation models”, Int. J. Production Economics, 96 (2005) 381-395.

Roy D., Anciaux D., Monteiro T. \& Ouzizi L. (2004), Multi-agent architecture for supply chain management, Journal of Manufacturing Technology Management (formerly IMS) - Special Issue on Logistics and Supply Chain Management with Artificial Intelligent Techniques, vol. 15, n8, pp. 745-755.

Schmitz J., Platts K.W. (2004), "Supplier logistics performance measurement: Indications from astudy in the automotive industry”, Int. J. Production Economics 89 (2004) 231-243.

Teti R., D’Addona D. (2006), "Emergent synthesis in supply network tool management”, Advanced Engineering Informatics 20 (2006) 233-246.

Türkay M., Oruç C., Fujita K. \& Asakura T. (2004). "Multi-company collaborative supply chain management with economical and environmental considerations”, Computers and Chemical Engineering, 28, 985-992.

Wu N., Su P. (2005), "Selection of partners in virtual enterprise paradigm”, Robotics and Computer-Integrated Manufacturing, 21, 119-131.

Yonghui, F., Rajesh, P. (2004), "Supply-side collaboration and its value in supply chains”, European Journal of Operational Research, 152 (2004) 281-288. 
Zhejun G. (2008), “An economic evaluation model of supply chain flexibility”, European Journal of Operational Research, 184 (2), p.745-758, Jan 2008. 